\title{
Insulin-Like Growth Factor-IIAs A Tumour Marker In Patients With Hepatocellular Carcinoma
}

\author{
Naglaa El-Toukhy ${ }^{1}$, Badawy A. Abdul Aziz, ${ }^{1}$ Abdelmoneam Ahmed ${ }^{2}$ \\ and Asmaa $\mathrm{Adel}^{3 *}$ \\ ${ }^{I}$ Department OfHepatology, Gastroenterology And Infectious Diseases, Faculty Of Medicine, \\ Benha University, Egypt. \\ ${ }^{2}$ Department Of Internal Medicine, FacultyOf Medicine, Benha University, Egypt. \\ ${ }^{3}$ Department Of Clinical And Chemical Pathology, Faculty Of Medicine, Benha University, Egypt.
}

\begin{abstract}
Hepatocellular carcinoma (HCC) is one of the most common cancer worldwide that causes death and in Egypt the burden of HCC is increasing. Prognosis depends on tumor stage. Insulin-like growth factors (IGFs) play an important role in cancer risk. IGF-II is a polypeptide involved in the proliferation and differentiation of normal, transformed and malignant hepatocyte. It is anticipated that HCC may produce IGFII, and serum IGF-II level may increase in patients with HCC so can be used as a serological test for the diagnosis of HCC. The aim was to assess the value of serum IGF-II in Egyptian patients with HCC. This study was included 40 patients with HCC, 30 patients with liver cirrhosis and 18 healthy controls. For all groups we studied clinical data, image findings, serum alpha fetoprotein(AFP) levels detected by enzyme immunoassay(EIA) kit and IGF-II serum levels were quantified using ELIZA technique. Tumor imaging characteristics of HCC including size, number and site were assessed. Tumor staging was done using Okuda ,Tokyo staging systems,CLIP and VISUM. The results showed that IGF-II values were higher in HCC cases than cirrhotics $(P 1=<0.001)$, higher in HCC than control $(P 2=0.003)$ but no significant difference between cirrhotics\& control $(P 2=0.869)$, with better diagnostic sensitivity and specificity for HCC group over nonHCC group (cirrhotic group and healthy control) with slightly better prognosis than AFP, these results suggest that IGF-II could be a potential diagnostic and prognostic marker for HCC investigations.
\end{abstract}

Keywords:Hepatocellular Carcinoma, IGF-II and Alpha fetoprotein.

\section{Introduction}

Hepatocellular carcinoma (HCC) is the sixth most common cancer worldwide and the third most common cause of cancer death

[1].In Egypt, HCC is the second most common cancer in men and the sixth most common cancers in [2]. Hospital-based studies in Egypt have reported an increase in the relative frequency of all liver - related cancers, from 4\% in 1993 to $7.3 \%$ in 2003 (Lehman and Wilson, 2009) and the increased survival rate among patients with cirrhosis allowing time for some of them to develop HCC

[2].Prognosis for patients with HCC depends on tumor stage, with curative therapies only available for patients detected at an early stage, patients detected at an early stage can achieve 5-year survival rates of $70 \%$ with transplant or resection, whereas those with advanced HCC are only eligible for palliative treatments and have a median survival of less than one year

[3].Up to $20 \%$ of HCC do not produce alphafetoprotein (AFP) even when very large (Ryder, 2003) and slight increase are usual in acute hepatitis, chronic hepatitis and cirrhosis and overlaps can cause diagnostic difficulties [4].Insulin-like growth factors (IGFs) play an important role in cancer risk[5]. Insulin-like growth factor II (IGFII) is a polypeptide involved in the proliferation and differentiation of normal, transformed and malignant hepatocyte

[6].Incresed expression of IGF-II at both mRNA and protein levels has been demonstrated in HCC tissues [7].Circulating IGF-II levels may decrease after transcatheter arterial chemoembolisation in patients with HCC [8].It is anticipated that HCC may produce IGF-II, and serum IGF-II level may increase in patients with HCC

\section{Patients And Methods}

This prospective observational study was carried out on 88 cases, classified into: Group( I) included 40 patients with hepatocellular carcinoma diagnosed by ultrasound (U/S) and/or confirmed by Triphasic Computed Tomography (CT) and Group (II) included 30 patients with cirrhosis diagnosed by clinical, laboratory, and U/S assessment. Admitted to gastroenterology, hepatology and infectious diseases \& internal medicine departments of Benha University Hospital during the period from November 2014 to May 2015 . Third group 18 apparently healthy subjects (without HCC or cirrhosis and with normal imaging) served as controls. 
The clinical/pathological data of the patients were recorded, including age, sex, viral infections $\{$ Hepatitis C Virus (HCV) and Hepatitis B Virus (HBV)\}, alcohol intakes, biochemical liver function test results, and AFP levels. Severity of liver cirrhosis by using Modified Child score \&MELD score \&Updated MELD score $(1.27 \times \log (1+$ creatinine $\mathrm{mg} / \mathrm{dl})+0.94 \times \log (1+$ bilirubin $\mathrm{mg} / \mathrm{dl})+1.66 \times \log (1+\mathrm{INR})$, And Veinna survival model for HCC (VISUM-HCC) (Sharma et al.,2008). HCC was diagnosed by abdominal US and serum AFP, with or without triphasicCT scan and/or liver histopathology. AFP was assayed by an enzyme immunoassay (EIA) Kit (Roche Mannheim, Germany). Tumor characteristics were detected by abdominal US with or without CT scan (including tumor size, number, site, halo sign and neovascularization). Tumor staging was done using Okuda [10], Tokyo [11]staging systems \} and Cancer of the Liver Italian Program (CLIP) scoring system.

2.1 Blood sampling and biochemical assays:Fasting venous blood samples $(5 \mathrm{ml})$ were collected by trained laboratory technicians. A portion of blood was allowed to clot and then centrifuged at $3500 \mathrm{~g}$ for $5 \mathrm{~min}$ to separate the serum used for assessment of aspartate aminotransferase (AST), alanine aminotransferase (ALT), and g-glutamyltranspeptidase (GGT), total bilirubin, direct bilirubin, albumin, creatnine and glucose concentrations were assayed using Beckman CX4 chemistry analyzer (NY, USA, supplied by the Eastern Co. For Eng. \&Trade-Giza, Egypt). Viral infection status ( HCVAb and HBS Ag) were measured using Abbott, Axyam (USA, Supplied by al kamalcompany). Serum AFP level was determined using an enzymelinked binding protein assay kit. All assays were performed induplicate according to the manufacturer's instructions. Serum aliquots were stored at $80 \_C$ until assayed and thawedimmediately before the measurements levels. Another portion of blood was collected in vacutainer tubes containing EDTA to measure ILG-II.

2.2 Quantification of Human Insulin-like Growth Factor II (IGF-II):The test is quantitative level of IGF-II in the sample by ELISA, adopt purified human IGF-II to coat microtitre plate, make solid-phase antibody, then add samples or standards to wells with a labeled antibody specific to IGF-II, then add labeled HRP to the well. After washing completely, add TMB substrate solution, TMB substrate becomes blue color in wells that contain antibody-antigen-enzyme-antibody complex, reaction is terminated by the addition of a stop solution and the color change is measured at a wavelength of $450 \mathrm{~nm}$. The concentration of IGF-II in the samples is then determined by comparing the O.D. of the samples to the standard curve. (Glory science Co., Ltd,USA).

2.3 statistical analysis: The collected data were summarized in terms of mean \pm Standard Deviation (SD) and range for quantitative data and frequency and precentage for qualitative data. Comparisons between the different study groups were carried out using the Chi-square test $\left(\chi^{2}\right)$ and Fisher Exact test (FET) to compare proportions as appropriate. The Student t-test $(t)$ was used to detect difference in the mean between two parametric data, while the Mann-Whitney test (z) was used to compare two non-parametric data.

Receiver Operating Curve (ROC) analysis was carried out to evaluate the diagnostic performance of AFP and IGF-II levels for HCC screening among cirrhotic patients. The best cutoff point and the correspending sensitivity and specificity, Postive Predictive Value (PPV), Negayive Predictive Value (NPV) and Area Under the Curve (AUC) were estimated.Spearman Correlation coefficient (rho; $\rho$ ) was used to test for the correlation between AFP and IGF-II and estimated parameters.After the calculation of each of the test statistics, the correspending distribution tables were consulted to get the "P" (probability value). Statistical significance was accepted at $\mathrm{P}$ value $<0.05$ (S). A P value $<0.001$ was considered highly significant (HS) while a $\mathrm{P}$ value $>0.05$ was considered non- significant.The statistical analysis was conducted using STATA/SE version 11.2 for Windows (STATA corporation, College Station, Texas).

\section{Results}

This study included 70 consecutive patients with HCC and 18 apparently healthy subjects. The epidemiologic characteristics of the two patients' groups were summarized in table 1 . The mean age of HCC patients was $54.6 \pm 6.55$ years with a range between $43-73$ years. In liver cirrhosis patients the mean age was $45.27 \pm 5.77$ years with a range between 28-55 years. Therewas a significant difference in the mean ages of HCC patientgroup, liver cirrhosis $(\mathrm{p}=<0.001)$. There was male predominance among the patients with HCC, 33 men (82.5) versus 7 women (17.5) with a male-to-female ratio of 4.7:1, in the liver cirrhosis patients there was 12 (40\%) males versus $18(60 \%)$ females, with a male-to-female ratio of $0.6: 1$ and there was significant difference in the sex ratios of HCC patients and liver cirrhosis patients $(\mathrm{p}=<0.001)$. As regards residence, occupation and smoking there was no significant difference $(\mathrm{p}=0.49,0.32,0.36$ respectively). The severity of liver cirrhosis assessed by child - Pugh classification table 2, most cases of HCC was Child B rather than Child A\&C, but the frequency of Child A was predominant in cirrhotic patients than in HCC with statistical significance $(\mathrm{p}=<0.04)$. Also The severity of liver cirrhosis assessed by MELD, uMELD scores among the studied patients table 3 showed that both scores were significantly higher in HCC patients $(\mathrm{p}=0.001)$ (Table 1). Tumor imaging characteristics of HCC patients were illustrated intable4. 
Table 1. Demographic features of the studied patients.

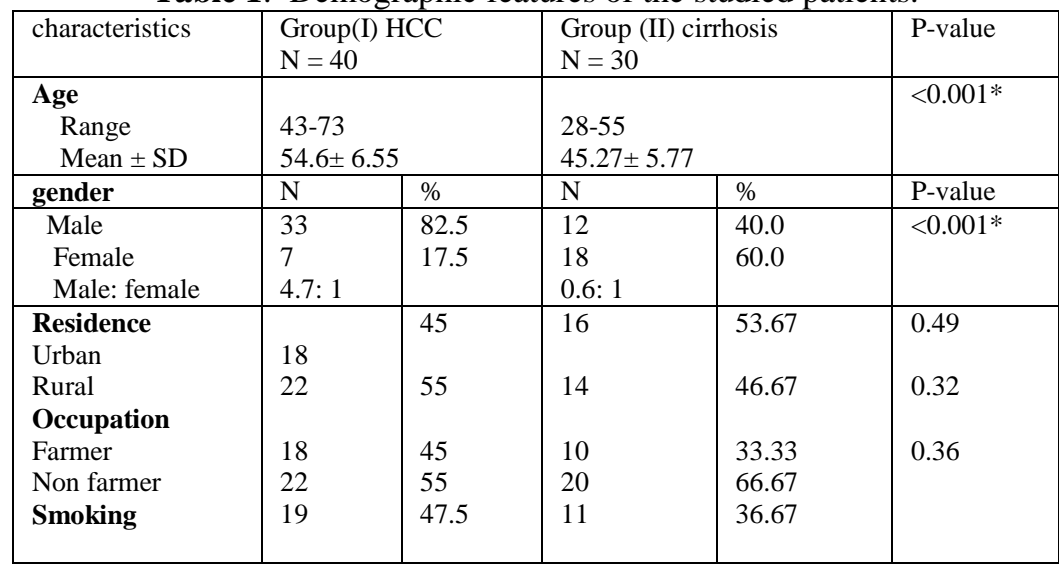

*=Significant, $\mathrm{SD}=$ standard deviation.

Table 2.The severity of liver cirrhosis assessed by child - Pugh classification among the studied patients.

\begin{tabular}{|l|l|l|l|l|l|}
\hline Child grade & \multicolumn{2}{|l|}{$\begin{array}{l}\text { Group (I) HCC } \\
\text { N= 40 }\end{array}$} & \multicolumn{2}{|l|}{$\begin{array}{l}\text { Group } \\
\text { cirrhosis } \\
\text { N= 30 }\end{array}$} & (II) \\
\cline { 2 - 5 } & $\mathbf{N}$ & \% & N & \% & \\
\hline Child A & 13 & 32.5 & 17 & 56.67 & $\mathbf{0 . 0 4 *}$ \\
Child B & 20 & 50 & 12 & 40 & 0.40 \\
Child C & 7 & 17.5 & 1 & 3.33 & 0.06 \\
\hline
\end{tabular}

Table 3 . The severity of liver cirrhosis assessed by MELD \&uMELD scores

\begin{tabular}{|l|l|l|l|l|l|}
\hline \multirow{2}{*}{} & \multicolumn{2}{|l|}{$\begin{array}{l}\text { Group (I) HCC } \\
\text { N= 40 }\end{array}$} & \multicolumn{2}{l|}{$\begin{array}{l}\text { Group (II) cirrhosis } \\
\text { N= 30 }\end{array}$} & \\
\cline { 2 - 5 } & Range & Mean \pm SD & Range & Mean \pm SD & \\
& & & & & \\
\hline MELD & $7-23$ & $12.57 \pm 3.97$ & $6-24$ & $8.77 \pm 3.63$ & $<0.001 *$ \\
uMELD & $1.08-2.17$ & $1.43 \pm 0.26$ & $0.9-1.9$ & $1.11 \pm 0.23$ & $<\mathbf{0 . 0 0 1 *}$ \\
\hline
\end{tabular}

MELD=model of end stage liver disease, $u$ MELD=updated MELD.

Table 4 .C T finding and tumor characteristics in HCC patients.

\begin{tabular}{|c|c|c|c|}
\hline & & $\begin{array}{l}\text { Gro } \\
\mathbf{N}=\end{array}$ & \\
\hline & & $\mathbf{N}$ & $\%$ \\
\hline & & 40 & 100 \\
\hline & & 38 & 95 \\
\hline & & 17 & 42.5 \\
\hline PY & & 7 & 17.5 \\
\hline & n number & & \\
\hline & Single & 25 & 62.5 \\
\hline & Multiple & 15 & 37.5 \\
\hline Sit & & & \\
\hline & Right Lobe & 25 & 62.5 \\
\hline & Left lobe & 6 & 15 \\
\hline & Both lobes & 9 & 22.5 \\
\hline $\mathbf{S i z}$ & & & \\
\hline & $<3 \mathrm{~cm}$ & 16 & 40 \\
\hline & $3-5 \mathrm{~cm}$ & 9 & 22.5 \\
\hline & $>5 \mathrm{~cm}$ & 15 & 37.5 \\
\hline
\end{tabular}

PVT=portal vien thrombosis

Table 5.Tumor staging.

\begin{tabular}{|l|l|l|}
\hline \multirow{2}{*}{ Stage } & \multicolumn{2}{|l|}{$\begin{array}{l}\text { Group (I) HCC } \\
\text { N= 40 }\end{array}$} \\
\cline { 2 - 3 } & $\mathbf{N}$ & $\%$ \\
\hline Okuda staging system & 14 & 35 \\
\hline I & 19 & 47.5 \\
II & 7 & 17.5 \\
III & CLIP staging system & \\
\hline &
\end{tabular}




\begin{tabular}{|l|l|l|}
\hline & 8 & 20 \\
I & 26 & 65 \\
III & 6 & 15 \\
\hline & & \\
\hline I & VISUM staging system & \\
II & 28 & 70 \\
III & 11 & 27.5 \\
\hline & 1 & 2.5 \\
\hline Early $<\mathbf{5}$ & Tokyo staging system & \\
Advanced $\square \mathbf{5}$ & 21 & 52.5 \\
\hline
\end{tabular}

Table 6 .AFP and IGF-II values in the studied groups.

\begin{tabular}{|c|c|c|c|c|c|c|c|}
\hline \multirow[t]{2}{*}{ Marker } & \multicolumn{2}{|c|}{$\begin{array}{l}\text { Group (I) HCC } \\
\mathbf{N}=\mathbf{4 0}\end{array}$} & \multicolumn{2}{|c|}{$\begin{array}{l}\text { Group (II) cirrhosis } \\
\mathbf{N}=\mathbf{3 0}\end{array}$} & \multicolumn{2}{|c|}{$\begin{array}{l}\text { Group (III) control } \\
\mathrm{N}=18\end{array}$} & \multirow[t]{2}{*}{ P value } \\
\hline & Range & Mean \pm SD & Range & Mean \pm SD & Range & Mean \pm SD & \\
\hline $\begin{array}{l}\text { IGF-II } \\
\text { (ng/ml) }\end{array}$ & $158.6-9691$ & $\begin{array}{l}1784 \\
\pm \\
2430\end{array}$ & $86.5-904.2$ & $\begin{array}{l}436.91 \\
\pm \\
264.1\end{array}$ & $91.3-838$ & $\begin{array}{l}360.2 \\
\pm \\
258.89\end{array}$ & $<0.001 *$ \\
\hline $\begin{array}{l}\text { AFP } \\
(\mathrm{ng} / \mathrm{ml})\end{array}$ & $1.5-3000$ & $\begin{array}{l}317.5 \\
\pm \\
617\end{array}$ & $0.99-77.8$ & $\begin{array}{l}10.64 \\
\pm \\
18.33\end{array}$ & $1.2-15.5$ & $\begin{array}{l}3.64 \\
\pm \\
3.21\end{array}$ & $<0.003 *$ \\
\hline
\end{tabular}

$\mathrm{AFP}=$ Alpha-fetoprotein,IGF-II= insulin-like growth factor-II

Abdominal CT showed Cirrhosis was present in $100 \%$ of cases with HCC, focal lesions by CT tend to be single (62.5), more in right Lobe (62.5), <3 cm in diameter (40) and PVT was present in $17.5 \%$ 0f cases. Regarding Okuda, and CLIP staging systems, most of HCC patients were relatively at advanced stage of the disease but as regard Tokyo staging system most HCC cases were early Tokyo stage table 5. As regards AFP levels, HCC patients had the highest mean value $(317.5 \pm 617 \mathrm{ng} / \mathrm{mL})$, with a significantly higher values $(\mathrm{p}<0.003)$, than the mean of AFP values in both liver cirrhosis patients $(10.64 \pm 18.33 \mathrm{ng} / \mathrm{mL})$ and healthy control $(3.64 \pm$ $3.21 \mathrm{ng} / \mathrm{mL})$ groups. As regards IGF-II values were higher in HCC cases than cirrhotics $(\mathrm{P} 1=<0.001)$, higher in HCC than control (P2=0.003), but no significant difference between cirrhotics\& control $(\mathrm{P} 2=0.869)$ table\&fig. 1.

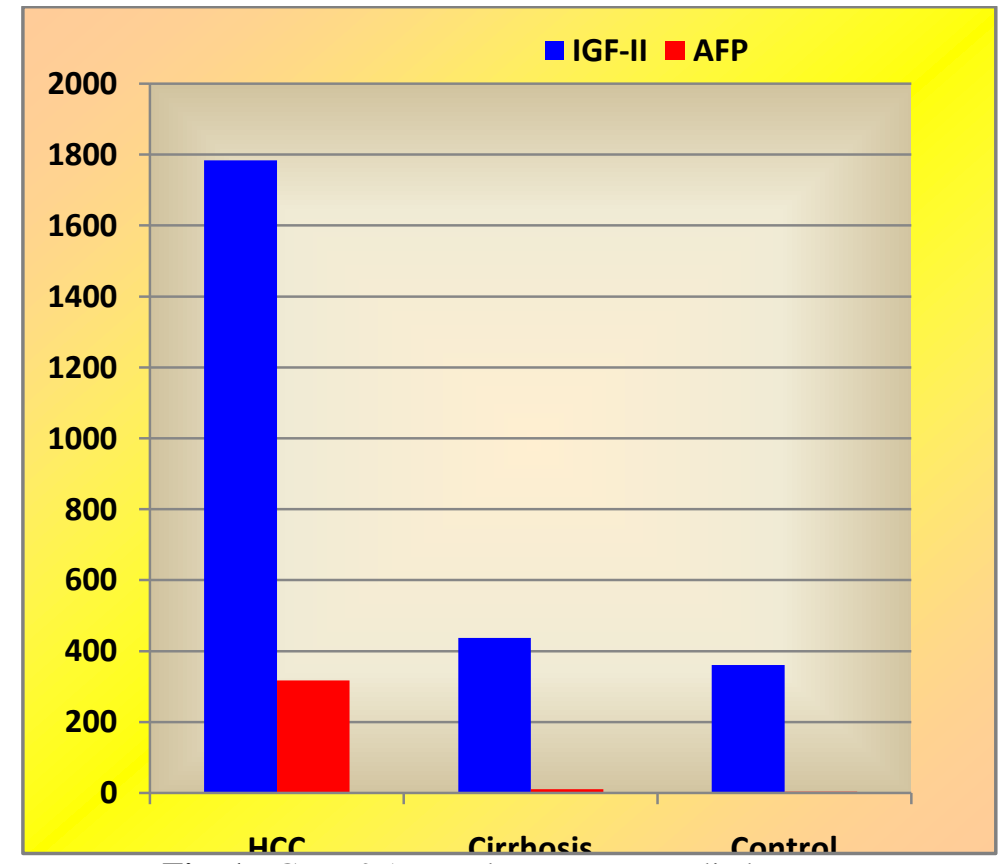

Fig. 1. IGF-II\&AFP values among studied groups

In the receiver operating curve (ROC), the area under curve (AUC) for AFP was $80.7 \%$ when we use $6.15 \mathrm{ng} / \mathrm{mL}$ as a cutoff point which gives the optimum balance between sensitivity, specificity the sensitivity was $75 \%$ and a specificity of $82 \%$. with PPV $96.9 \%$ and NPV $94.7 \%$. For IGF-II, the area under curve (AUC) was $84 \%$ when we use 530 cycle threshold as a cutoff point which gives the optimum balance between sensitivity, specificity the sensitivity was $87.5 \%$ and a specificity of $62.5 \%$ with PPV86.5\% and NPV $78.3 \%$. (Fig. 2)\& Table 3. 


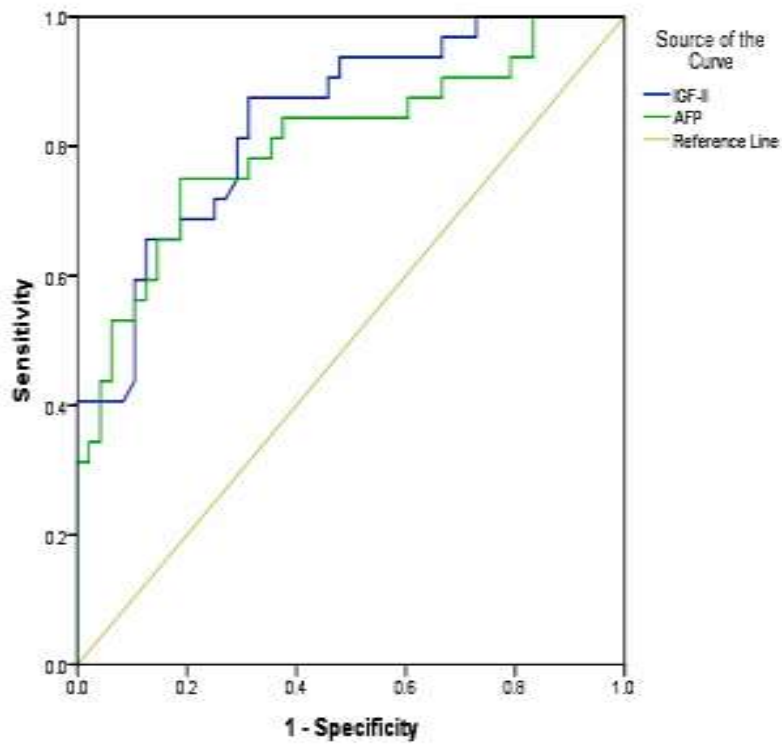

Fig. 2. In the receiver operating curve (ROC), the area under curve (AUC) for AFP was $80.7 \%$ when we use $6.15 \mathrm{ng} / \mathrm{mL}$ as a cutoff point which gives the optimum balance between sensitivity, specificity the sensitivity was $75 \%$ and a specificity of $82 \%$. with PPV $96.9 \%$ and NPV $94.7 \%$. For IGF-II, the area under curve (AUC) was $84 \%$ when we use 530 cycle three shold as a cutoff point which gives the optimum balance between sensitivity, specificity the sensitivity was $87.5 \%$ and a specificity of $62.5 \%$ with PPV86.5\% and NPV $78.3 \%$. (Fig. 2)\& Table 3.

As regard prognosis, There was significant positive correlation between AFP and tumor number, IGFII, Tokyo and VISUM staging system among $\operatorname{HCC}(\mathrm{P}=0.008,0.003,0.023,0.04$ respectively $)$. There was significant positive correlation between IGF-II and Child score, tumor number, AFP and Tokyo staging system among $\mathrm{HCC}$ cases( $\mathrm{p}=0.031,0.042,0.003,0.02$ respectively) figure 3,4 .

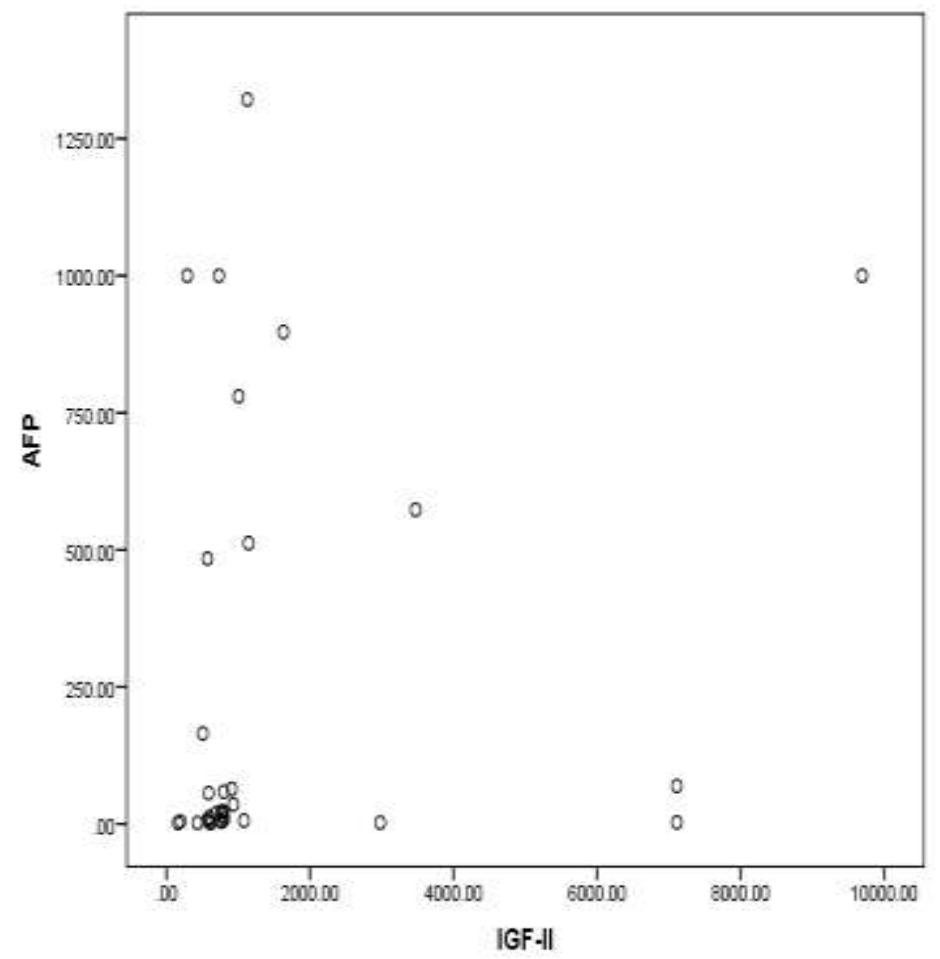

Fig. 3.Correlations between IGF-II\&AFP values among HCC cases. 


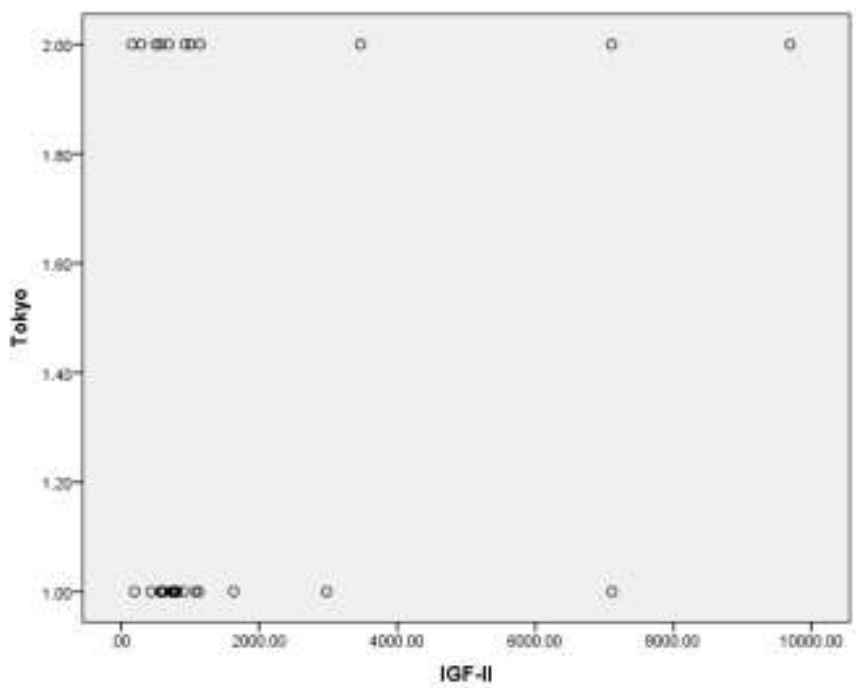

Fig. 4.Correlations between IGF-II values\&Tokyo stage among HCC cases.

\section{Discussion}

Worldwide, HCC is the fifth most common cancer in men and the seventh in women, with more than 748,000 new cases being diagnosed each year, accounting for $9.2 \%$ of all new global cancer cases [12] and[13]

Hepatocellular carcinoma (HCC) is the sixth most common cancer worldwide and the third most common cause of cancer death [1]

Prognosis for patients with HCC depends on tumor stage, with curative therapies only available for patients detected at an early stage. In this study we aimed at evaluating the diagnostic and prognostic value of IGF-II in patients with HCC.

In the current study, $\mathrm{HCC}$ commonly presented in males more than females with a male to female ratio 4.7:1, this was in agreement with[14] and[15] who reported that males predominated with male to female ratio of 4.7:1 and 5:1 among HCC patients respectively. The higher incidence of HCC in males might be due to the stimulatory effects of androgen and the protective effect of oestrogen. The biological activity of natural progesterones on HCC is contraverse. Concerning the age, patients with HCC had a mean age of 54.6 years with a range between $43-73$ years old, while cirrhotic patients are younger with a mean age of 45.2 years and ranging between $28-55$ years old.

These results were in agreement with[16]who reported that the age of the HCC patients ranged between 42 and 70 years and mean is 58.7 years, and also with[17]who reported that the peak age group for HCC was from $50-70$ years with a mean age of 58.7 years.

In Egyptian series by [18]and[19] the peak age was 56 years and 55.74 years respectively.

In this study, $55 \%$ of HCC cases were from rural areas, this result was in agreement with [20] who stated that the incidence of HCC is more common in rural areas than urban.

This may be explained by increasing the incidence of exposure to many risk factors such as HCV and HBV infection, pesticides and diets contaminated by aflatoxin in rural areas [21].

In contrast,[2]stated that most of HCC cases resided in urban areas due to better access to medical facilities.

In this study, only $45 \%$ of HCC cases were farmers while $55 \%$ of HCC cases were non farmers, these results are in agreement with [22] who reoprted that only $41 \%$ of HCC cases were farmers.

These results were supported by [23] who stated that the relation between occupation and HCC has not been extensively studied, but prolonged exposure to toxic chemical substances may increase HCC incidence.

In contrast, [24] reported that HCC is more common in farmers (59.3\%) compared with non farmers (40.7\%). This may be due to increased exposure to carcinogenic factors especially HCV infection and lack of medical facilities.

The current study showed that $47.5 \%$ of HCC cases had a history of smoking, this result are in agreement with (Hara et al., 2008) who found that $46.8 \%$ of HCC cases are smokers especially in males, additionally [25] who found that $50 \%$ of HCC cases are smokers.

However, [26]reported that smoking was found in 64\% of Egyptian patients with HCC compared to $38 \%$ in patients with liver cirrhosis.

Although alcoholism is a well identified risk factor for HCC as increasing level of alcohol consumption were associated with increased yearly incidence rates for HCC [27], however this role was not clear in this study as there is no history of alcohol intake between HCC cases. 
This may be due to different socioeconomic and religious status that forbidden alcohol intake.

However, [18] in Egyptian series reported that $4.9 \%$ of HCC cases had history of alcohol intake. In contrast Alves et al. (2011) in their study in Brazil found that $22 \%$ of HCC patients were alcoholic's.

The clinical picture of HCC is very variable [4], in this study, the presenting symptoms in HCC group mostly were abdominal pain, yellowish discoloration of sclera, weight loss and abdominal enlargement, these results were constantly with that reported by [18], [22] and[28].

In this study, history of blood transfusion was $32.5 \%$ among $\mathrm{HCC}$ group, this result goes in agreement with [29] who stated that $28 \%$ of HCC cases had a history of blood transfusion.

The prominent physical signs in HCC patients were jaundice and hard liver, this goes in agreement with [30] who stated that jaundice and hard liver are common signs of HCC.

Physical examination usually shows other signs of cirrhosis with portal hypertension, including spider angiomas, palmar erythema, ascites, lower limb oedema, and splenomegaly, this goes in agreement with [31]

Concerning blood picture in this study hemoglobin, WBCs and platelets were lower in HCC patients than in cirrhotics. This results go in agreement with [32] who reported the same results exactly.

According to the liver biochemical profile in this study AST and serum bilirubin were higher in HCC patients. This results goes in agreement with [33] who reported that AST and serum bilirubin are higher in HCC patients than cirrhotics.

Other liver biochemical profile in this study as serum albumin was lower in HCC patients than cirrhotics, also prothrombin time was prolonged in HCC patients than cirrhotics. This results in agreement with [34] and[16] who reported the same results.

Concerning seroprevalence of HBsAg positivity among HCC cases none of cases were positive. This decrease of HbsAg positivity may be partially attributed to successful control measures of blood transfusion and vaccination and partially to the development of mutant or occult $\mathrm{HBV}$ infection, which requires costly assays for diagnosis [35]

However, in Egyptian studies by [18] and[20] reported that lower prevalence of $2.4 \%$ and $2.51 \%$ of $\mathrm{HCC}$ cases were $\mathrm{HBsAg}$ positive respectively

In this study, regarding the seroprevalence of HCVAb positivity among $\mathrm{HCC}$ cases, $90 \%$ of cases were positive for $\mathrm{HCV} \mathrm{Ab}$, this was in agreement with other egyptian series by [24]and[20] who reported that 89.19\% and $91.32 \%$ of HCC cases were HCVAb positive respectively, also similar results by [36] and[17 ]who documented that $89.2 \%$ and $93 \%$ of HCC cases were HCVAb positive respectively.

These results are supported by [37] who stated that in areas with an intermediate rate of liver tumours such as southern Europe, Egypt and Japan, HCV is the predominant cause of HCC.

In this study, most of the patients with HCC (50\%) were Child B, followed by Child A (32.5\%) then Child C (17.5\%), these results are in agreement with [38] who reported that $(53.1 \%)$ of HCC cases were Child B followed by Child A (31.3\%) then Child C (12.5\%), and [39] who reported that (40\%) Of advanced HCC cases were Child B, followed by Child A (32.7\%) then Child C (27.3\%)

In contrast, [33] reported that (61.06\%) of HCC cases were Child C, followed by Child A (20.3\%) then Child B (18.5\%).

This difference may be attributed partially to the type of patients and partially to the development of screening program for early detection of HCC in the other countries.

According to MELD and uMELD scores, in this study the mean scores for patients with HCC were 12.57 and 1.43 respectively, while the mean scores for patients with cirrhosis were 8.77 and 1.11 respectively, these results are nearly similar to that of [40] who reported that the mean MELD and uMELD scores for patients with HCC were 15.3 and 3.63 respectively, this may be explained by the fact that HCC comes on top of severe liver disease.

Abdominal ultrasonography was done to evaluate the liver status in the studied patients and all of the patients (100\%) with HCC had sonographic evidence of liver cirrhosis, this goes in agreement with [40]and [28] who documented that cirrhosis of the liver is present in $100 \%$ of patients with HCC.

Also, [41] stated that $90-95 \%$ of people who develop HCC have underlying cirrhosis.

This was supported by [42] who documented that cirrhosis is the most important risk factor for HCC as more than $(80 \%)$ of the HCC cases occur in the setting of cirrhosis.

Seven patients $(17.5 \%)$ in this study were found to had portal vein thrombosis, this finding goes in agreement with

[35] and[28] who reported that $18 \%$ and $17.2 \%$ of HCC cases had portal vein thrombosis respectively.

A higher finding was reported by [43]and[19] who reported that $28 \%$ and $28.2 \%$ of HCC cases had portal vein thrombosis respectively as a considerable proportion of HCC cases in these studies had advanced disease. 
Twenty five, representing $62.5 \%$ of HCC cases had single focal hepatic lesion, while multiple hepatic focal lesions were present in $37.5 \%$ of the cases, these results were in agreement with [44]and[22] who mentioned that single lesions found in $62.3 \%$ and $61 \%$ respectively.

Also, [40]documented that $66.7 \%$ patients had single lesion and $33.3 \%$ had multiple lesions.

In the present study $40 \% \mathrm{HCC}$ cases had their tumor size less than $3 \mathrm{~cm}$ while $22.5 \%$ had their tumor size between $3 \mathrm{~cm}$ and $5 \mathrm{~cm}$, and $37.5 \%$ had tumor size of more than $5 \mathrm{~cm}$, meaning that $60 \%$ of patients had tumor size of more than $3 \mathrm{~cm}$.

This goes in agreement with [45 ]who reported that $49 \%$ with tumor size less than $3 \mathrm{~cm}, 23 \%$ with tumor size between 3 and $5 \mathrm{~cm}$, and $28 \%$ with tumor size more than $5 \mathrm{~cm}$, and [46] who documented that $35 \%$ with tumor size less than $3 \mathrm{~cm}$ and $65 \%$ with tumor size more than $3 \mathrm{~cm}$.

In this study, the right lobe was predominantly more affected by tumor $(62.5 \%)$ than left lobe $(15 \%)$ and both lobes $(22.5 \%)$, these results were in agreement with [47] who mentioned that $58.3 \%$ of his cases had their focal lesions within the right lobe, $18.3 \%$ within the left lobe, and $23.4 \%$ in both lobes, also [28] who reported that $65.5 \%$ of his cases had their focal lesions within the right lobe, $12 \%$ within the left lobe, and $22.5 \%$ in both lobes.

One patient (2.5\%) of HCC cases in this study was found to had lymph node enlargement, this goes in agreement with [47 ]who mentioned that lymph node invasion or distant metastases was detected in $(5.5 \%)$ patients at diagnosis.

Concerning Okuda staging, most of HCC cases were stage II (47.5\%) followed by stage I (35\%) then stage III (17.5\%), these results were in agreement with [33] who reported that stage I was $37.2 \%$, stage II was $42.5 \%$ and stage III was $20.3 \%$ and [47] who documented that stage I was $34.8 \%$, stage II was $45.8 \%$ and stage III was $19.4 \%$.Concerning CLIP staging, most of HCC cases were presented at the intermediate stage $(65 \%)$ comparing to the patients presented at the early stage (20\%) and the advanced stage (15\%) respectively.

This goes in agreement with [48] who reported that (53.5\%) of HCC cases were at intermediate stage, followed by the early stage $(29 \%)$ then the advanced stage $(17.5 \%)$.

Also, [49] who mentioned that (72.5\%) of HCC cases were at intermediate stage, followed by the early stage $(18 \%)$ then the advanced stage (8.5\%), similarly Shao et al. (2012) who documented that most of HCC cases $(66 \%)$ were at intermediate stage followed by the advanced stage (24\%) then the early stage (10\%).

According VISUM staging, most of HCC cases were stage I, this result was in agreement with [50 ] who reported that most of cases were in stage I.

According to Tokyo staging, most of HCC patients were presented at early stage (52.5\%) comparing to the patients presented at advanced stage $(47.5 \%)$.

Higher results were reported by [51] who mentioned that most of HCC cases $(85.9 \%)$ were presented at early stage.

AFP is the most established tumor marker in $\mathrm{HCC}$ and the gold standard by which other markers for the disease are judged [52].

In the current study, AFP in $\mathrm{HCC}$ cases had a mean value of $317.5 \mathrm{ng} / \mathrm{ml}$ which was statistically higher than that of patients with cirrhosis $(10.6 \mathrm{ng} / \mathrm{ml})$ and control $(3.6 \mathrm{ng} / \mathrm{ml})$ subjects, these results are in agreement with [53] who reported that AFP in HCC cases had a mean value of $384.6 \mathrm{ng} / \mathrm{ml}$ which was statistically higher than that of patients with cirrhosis $(6.04 \mathrm{ng} / \mathrm{ml})$ and control $(2.9 \mathrm{ng} / \mathrm{ml})$ subjects.

Furthermore, similar results by [54] who reported that AFP in HCC cases had a mean value of 295.9 $\mathrm{ng} / \mathrm{ml}$ which was higher than that of patients with cirrhosis $(19.5 \mathrm{ng} / \mathrm{ml})$ and control $(5.9 \mathrm{ng} / \mathrm{ml})$.

ROC analysis of AFP used as a diagnostic test suggests that a value of about $6.15 \mathrm{ng} / \mathrm{ml}$ provides the optimal balance between sensitivity and specificity, however at this level the sensitivity is only $75 \%$ and the specificity is $82 \%$.

This goes in agreement with [53] who reported that sensitivity of AFP is about $79.7 \%$ and specificity is about $80.3 \%$ in HCC cases.

However, this value is considered to be within the normal level of serum AFP in adults which is less than $10 \mathrm{ng} / \mathrm{ml}[\mathbf{5 5}]$

Accordingly, the role of AFP in the diagnosis of HCC is limited, these results were supported by [56 ]who mentioned that AFP is not elevated in all patients with HCC, its sensitivity for detecting HCC ranges between $25 \%-60 \%$, and its specificity is also low because serum AFP can also be detected in patients with cirrhosis and chronic hepatitis.

This was supported by [57] who stated that AFP level are frequently normal in patients with small $\mathrm{HCC}$ and are not elevated in a significant portion in patients with early stage, potentially curable HCC. Also [58 ]concluded that the serum AFP level was a weak diagnostic predictor in HCC patients.

There is a debate in defining the AFP cut-off level for the diagnosis of HCC, an AFP value above 400$500 \mathrm{ng} / \mathrm{ml}$ has been considered to be diagnostic for HCC in patients with cirrhosis, however, such a cut-off value is problematic in absolute diagnostic terms, since high levels of this magnitude are not as common in the 
presence of smaller tumors $(<5 \mathrm{~cm})$ and furthermore, only $30 \%$ of HCC patients have levels higher than 100 $\mathrm{ng} / \mathrm{ml}$ in this context [59]

In this study, there was non-significant correlation between AFP and the severity of the liver disease (Child, MELD and uMELD scores), tumor size, Okuda and CLIP stages, this finding is supported by [58]and [18] who reported that no correlation between AFP and severity of the liver disease.

But there was significant positive correlation between AFP and tumor number, IGF-II, Tokyo and VISUM staging system among HCC cases, these were in agreement with [47] and [60]who reported that there was a significant positive correlation between AFP and tumor number.

Regarding AFP as a marker for HCC, our results supported by [58] Jwho concluded that serum AFP is a weak prognostic predictor in HCC patients and [61] stated that the value of AFP is limited in the diagnosis and prognosis of HCC.

There is a growing body evidence to indicate that IGF-II play an important role in cancer risk. The addition of an assay for IGF-II may bring a significant improvement in the detection of small HCC [9]

Concerning Insulin-like Growth Factor II (IGF-II) mean value, HCC cases had a mean value of (1784 $\mathrm{ng} / \mathrm{ml})$ which was higher than that of patients with cirrhosis $(436.9 \mathrm{ng} / \mathrm{ml})$ and control $(360.2 \mathrm{ng} / \mathrm{ml})$ subjects, these results were in agreement with Yao et al. (2013) who reported that IGF-II was significantly higher in HCC patients (mean $450.3 \mathrm{ng} / \mathrm{ml}$ ) than in cirrhosis (mean 174.2ng/ml) and healthy control (mean $149.7 \mathrm{ng} / \mathrm{ml}$ ).

Similar results by [62] who stated that mean value of IGF-II was higher $(888 \mathrm{ng} / \mathrm{ml})$ in HCC patients than in cirrhotics $(432 \mathrm{ng} / \mathrm{ml})$.

Also [63] reported that mean value of IGF-II was significantly higher in HCC group than in cirrhotics or in the normal control group.

ROC analysis of IGF-II used as a diagnostic test suggests that a value of $530 \mathrm{ng} / \mathrm{ml}$ provides the optimal balance between sensitivity and specificity, at this level the sensitivity is $87.5 \%$ and specificity is $62.5 \%$.

This goes in agreement with Aleem et al. (2012) who reported that at a cut-off value of $414 \mathrm{ng} / \mathrm{ml}$, the sensitivity and specificity of IGF-II in HCC patients were $75 \%$ and $60 \%$ respectively.

Also, [62] stated that the sensitivity and specificity of IGF-II in HCC patients was $73 \%$ and $64 \%$ respectively.

Also [64 ] stated that expression of IGF-II may be useful markers for diagnosis of HCC and its extrahepatic metastasis, and monitoring recurrence.

There was significant positive correlation between IGF-II and severity of liver disease (Child-Pugh grade), tumor number, AFP and Tokyo stage, this goes in agreement with [65] who reported that there was positive correlation between IGF-II and AFP, Child-Pugh grade and number of lesions in HCC patients.

Also, [66] stated that there was significant positive correlation between IGF-II and AFP.

IGF-II has a significant role in assessment of severity of liver disease, this was supported by [67]who reported that determination of serum IGF-II levels is of help in judgment of severity of liver diseases as well as outcome prediction.

There was no significant correlation between IGF-II and the size of the tumor, this goes in agreement with [63] and [68] who reported that there was no significant correlation between IGF-II and tumor size.

Regarding IGF-II as diagnostic and prognostic marker of HCC, these results suggest that IGF-II level could be a potential diagnostic and prognostic marker for HCC, this suggestion was supported by [9] and[69] who documented that IGF-II can be used as prognostic and diagnostic indicators for HCC as its level increases especially in patients with small HCC.

According to this study, IGF-II level is elevated in HCC patients than cirrhotics and apparently healthy subjects, with better diagnostic sensitivity and specificity for HCC group over non-HCC group (cirrhotic group and healthy control) with slightly better prognosis than AFP, these results suggest that IGF-II could be a potential diagnostic and prognostic marker for HCC investigations [70] .

\section{Conclusion}

IGF - II couldbeaccurate a sensitive and specific serum marker for diagnosing HCC.

\section{Consent}

All authors declared that written informed consent was obtained from the patients for publication of this paper.

Ethical Approval

Ethical clearance was obtained from BenhaUniversityHospital's ethics committee.

Competing Interests

Authors have declared that no competing interests exist. 


\section{References}

[1]. Dai, L.; Ren, P.; Liu, M.; Imai, H.; Tan, E.M. et al. Using immunomic approach to enhance tumor-associated autoantibody detection in diagnosis of hepatocellular carcinoma.Clin. Immunol.2014; 152: 127-139.

[2]. Omar, A.; Abou-Alfa, G.K.; Khairy, A. and Omar, H. Risk factors for developing hepatocellular carcinoma in Egypt. Chin. Clin.Oncol. 2013; 2(4): 43.

[3]. Padhya, K.T.; Marrero, J.A. and Singal, A.G. Recent advances in the treatment of hepatocellular carcinoma. Curr.Opin.Gastroenterol. 2013; 29(3): 285-292

[4]. Sherlock, S. and Dooley, J. Diseases of the liver and biliary system. Soliman, A.S.; Hung, C.W.; Tsodikov, A.; Seifeldin, I.A.; Ramadan, M. et al. Epidemiologic risk factors of hepatocellular carcinoma in rural region of Egypt. Hepatol. Int. 2010; 4: 681-690

[5]. LeRoith, D. and Roberts, C.T. The insulin-like growth factor system and cancer.CancerLett. 2003; 195: 127-137

[6]. Wang, C.S.; Lin, C.L.; Lee, H.C.; Chen, K.Y.; Chiang, M.F. et al. Usefulness of serum des-gamma-carboxyproyhrombin in detection of hepatocellular carcinoma. World J. Gastroenterol. 2005; 11(39): 6115-6119.

[7]. Fan Z.R.; Yang D.H.; Jun Cui J.; Han Rong Qin H.R; and Chun Chi HuangC.C. Expression of insulin like growth factor II and its receptor in hepatocellular carcinogenesis. World J Gastroentero, 2001;7(2):285 - 288.

[8]. Song, P.; Gao, J.; Inagaki, Y.; Kokudo, N.; Hasegawa, K. et al. Biomarkers: evaluation of screening for and early diagnosis of hepatocellular carcinoma in Japan and China. Liver Cancer. 2013; 2(1): 31-39.

[9]. Tsai, J.F.; Jeng, J.E.; Chuang, L.Y.; You, H.L.; Wang, L.Y. et al. Serum insulin-like growth factor-II as a serologic marker of small hepatocellular carcinoma. Scandinavian J. Gastroenterology.2005; 40: 68-75.

[10]. Okuda, K.; Ohtsuki, T.; Obata, H.; Tomimatsu, M.; Okazaki, N. et al. Natural history of hepatocellular carcinoma and prognosis in relation to treatment. Study of 850 patients.Cancer. $1985 ; 56(4)$ : 918-928.

[11]. Tateishi, R.; Yoshida, H.; Shiina, S.; Imamura, H.; Hasegawa, K. et al. Proposal of a new prognostic model for hepatocellular carcinoma: an analysis of 403 patients. Gut. 2005; 54: 419-425

[12]. Ferlay, J.; Shin, H.R.; Bray, F.; Forman, D.;Mathers, C. et al. Estimates of worldwide burden of cancer in 2008: GLOBOCAN 2008. Int. J. Cancer. 2010; 127(12): 2893-2917.

[13]. Jemal, A.; Bray, F.; Center, M.M.; Ferlay, J.; Ward, E. et al. Global cancer statistics. CA. Cancer J. Clin. 2011; 61(2): 69-90.

[14]. Sharaf-Eldin, M.; Salah, R.; Soliman, H.H.; Abdou, S.H.; Abd-Elsalam, S. et al. Aflatoxin as an environmental risk factor attributable to liver cancer in Nile Delta. Indian J. Med. Res. Pharm. Sci. 2016; 3(4): 2349-5340

[15]. Holah, N.S.; El-Azab, D.S.; Aiad, H.A. and Sweed, D.M. Hepatocellular carcinoma in Egypt: epidemiological and histooathologicalproperities. Menoufia Medical Journal. 2015; 28(3): 718-724

[16]. Baghdady, I.; Fouad, F.; Sayed, M.; Shoaib, A.; Salah, Y. et al. Serum markers for the early detection of hepatocellular carcinoma in patients with chronic viral hepatitis C infection. Menoufia Medical Journal ; 2014; 27(3): 544-550

[17]. Shaker, M. Epidemiology of HCC in Egypt. Gastroenterology and Hepatology.2016; 4(3).

[18]. Atta, M.M.; El-Masry, S.A.; Abdel-Hameed, M.; Baiomy, H.A. and Ramadan, N.E. Value of serum anti-p53 antibodies as a prognostic factor in Egyptian patients with hepatocellular carcinoma. ClinBiochem. 2008; 41: 1131-1139.

[19]. El-Shenawy, S.Z.; El-Sabawi, M.M.; Sheble, N.; Abd El-Raof, M.; Allam, M.M. et al. Diagnostic role of serum Glypican-3 as a tumor marker for hepatocellular carcinoma. Nature and Science. 2012; 10(4): 32-38.

[20]. Shaker, M.; Abdella, H.M.; Khalifa, M.O. and El Dorry, A.K. Epidemiological characteristics of hepatocellular carcinoma in Egypt: a retrospective analysis of 1313 cases. Liver Int. 2013; 33(10): 1601-1606.

[21]. Saleh, D.A.; Amr, S.; Jillson, I.A.; Wang, J.H.; Crowell, N. et al. Preventing hepatocellular carcinoma in Egypt: results of a Pilot Health Education I ntervention Study. BMC.Res. Notes. 2015; 8: 384

[22]. Gani, A.; Al-Mahtab, M.; Rahman, S. and Akbar, S. Characteristics features of HCC in Bangladesh and their public health implications. Euroasian J. Hepato-gastroenterol. 2013; 3(1): 28-30.

[23]. Uccello M, Malaguarnera G, Corriere T, Biondi A, Basile F, Malaguarnera M. Risk of Hepatocellular Carcinoma in Workers Exposed to Chemicals. Hepat Mon. 2012;12(10 HCC): e5943. DOI: 10.5812/hepatmon.5943.

[24]. Soliman A.S; Hung CW.; Tsodikov A.; - Seifeldin I. A.; Ramadan M.; Al-Gamal D.; Schiefelbein E.L.; Thummalapally P.; DeyS.and Ismail K. Epidemiologic risk factors of hepatocellular carcinoma in a rural region of Egypt. HepatolInt (2010) 4:681-690

[25]. Yun, Y.H.; Jung, K.W.; Bae, J.M.; Lee, J.S.; Shin, S.A. et al. Cigarette smoking and cancer incidence risk in adult men: National Health Insurance Corporation Study. Cancer Detect. Prev. 2005; 29(1): 15-24.

[26]. Bakir, A.S. and Ali-Eldin, Z.A. Is diabetes mellitus a risk factor for hepatocellular carcinoma in Egyptian patients? J. Am. Sci. 2012; 8: 353-358

[27]. Kawamura, Y.; Arase, Y.; Ikeda, K.; Akuta, N.; Kobayashi, M. et al. Effect of alcohol consumption on hepatocarcinogenesis in Japanese patients with fatty liver disease. Clin.Gastroenterol.Hepatol. 2016; 14(4): 597-605.

[28]. Omar, A.; Elbaz, T.M.; Shousha, H.I.; Ibrahim, M.M.; El-Shazli, M. et al. Survival and prognostic factors for hepatocellular carcinoma: an Egyptian Multidisciplinary Clinic experience. Asian Pac. J. Cancer Prev. 2014; 15(9): 3915-3920

[29]. AbdElmouttaleb, A.T.; Abd-Elatif, D.M.; Soliman, G.M.; Taher, M.S. and Abonar, A.A. Serum Micro RNA-122 as a biomarker for hepatocellular carcinoma in chronic hepatitis C virus patients.Cancer and Tumor.2015 ; 4(2): 25-33.

[30]. Di Bisceglie, A.M. Epidemiology and clinical presentation of hepatocellular carcinoma. J. Vasc. Interv.Radiol.2002; 13: 169-171.

[31]. Yang, J.D. and Roberts, L.R. Epidemiology and management of hepatocellular carcinoma. Infect. Dis. Clin. North. Am. 2010; 24(4): 899-919

[32]. Abd El Moety, H.A.; Maharem, D.A. and Gomaa, S.H. Serotonin: Is it a marker for the diagnosis of hepatocellular carcinoma in cirrhotic patients? Alexandria Journal of Medicine.2013; 49: 369-378.

[33]. Abu El Makarem, M.A.; Abdel-Aleem,A.; Saber, R.; Shatat, M.; Rahem, D.A. et al. Diagnostic significance of plasma osteopontin in hepatitis C virus-related hepatocellular carcinoma. Ann Hepatol. 2011; 10(3):296-305

[34]. Wong, V.W.; Chan, S.L.; Mo, F.; Chan, T.C.; Loong, H.H. et al. Clinical scoring system to predict hepatocellular carcinoma in chronic hepatitis B carriers. J. Clin. Oncol. 2010; 28(10): 1660-1665.

[35]. El-Zayadi, A.R.; Badran, H.M.; Barakat, E.M.; Attia, M.; Shawky, S. et al. Hepatocellular carcinoma in Egypt: a single center study over a decade. World J. Gastroenterol. 2005; 11(33): 5193-5198.

[36]. Schiefelbein, E.; Zekri, A.R.; Newton, D.W.; Soliman, G.A.; Banerjee, M. et al. Hepatitis C virus and other risk factors in hepatocellular carcinoma. Acta.Virol. 2012; 56(3): 235-240.

[37]. Michielsen, P.P.; Francque, S.M. and Dongan, J.L. Viral hepatitis and hepatocellular carcinoma. World J. of Surgical.2005; 3:27.

[38]. Alves, R.C.P.; Alves, D.; Guz, B.; Matos, C.; Viana, M. et al. Advanced hepatocellular carcinoma, review of targeted molecular drugs. ANNIAS of hepatology. 2011; 10(1): 21-27.

[39]. El-Sawy, A.A. Socoi-demographic factors related to advanced hepatocellular carcinoma: A single centre retrospective study. Indian J. of Medicine Research and Pharmaceutical Science. 2016; 3(3):6-13. 
[40]. Mohamed, A.A.; El-Toukhy, N.; Atta, M.M. and Salah, M.A. Glypican-3 as a tumor marker for hepatocellular carcinoma. J. of Applied Pharmaceutical Science. 2013; 3(6): 83-87.

[41]. Forner, A.; Llovet, J.M. and Bruix, J. Hepatocellular carcinoma. Lancet. 2012; 379: 1245-1255

[42]. Marrero, J.A.; Ahn, J. and Reddy, K.R. ACG clinical guideline: The diagnosis and management of focal liver lesions. Am. J. Gastroenterol. 2014; 109(9): 1328-1347

[43]. Cheung, T.K.; Lai, C.L.; Wong, B.C.; Fung, J. and Yuen, M.F. Clinical features, biochemical parameters, and virological profiles of patients with hepatocellular carcinoma in Hong Kong. Aliment PharmacolTher. 2006; 24(4): 573-583.

[44]. El-Zayadi, A.R.; Badran, H.M.; Shawky, S.; Emara, S.; El-Bareedy, A. et al. Effect of surveillance for hepatocellular carcinoma on tumor staging and treatment decisions in Egyptian patients. Hepatol. Int. 2010; 4(2): 500-506.

[45]. Gad, A.; Tanaka, E.; Matsumoto, A. and Kiyosawa, K. Ethnicity affects the diagnostic validity of alpha-fetoprotein in hepatocellular carcinoma. Asia-Pacific Journal of Clinical Oncology.2005; 1: 64-70.

[46]. Korah, T.; Badr, E.; Emara, M.; Kohla, M. and Michael, G. Relation between sex hormones and hepatocellular carcinoma. Andrologia.2016; 1-8.

[47]. Gomaa, A.L.; Hashim, M.S. and Waked, I. Comparing staging systems for predicting prognosis and survival in patients with hepatocellular carcinoma in Egypt. Plos One.2014; 9(3).

[48]. Collette, S.; Bonnetain, F.; Paoletti, X.; Doffoel, M.; Bouche,O. et al. Prognosis of advanced hepatocellular carcinoma: comparison of three staging systems in two French clinical trials. Ann. Oncol. 2008; 19(6): 1117-1126

[49]. Kaseb, A.O.; Abbruzzese, J.L.; Vauthey, J.N.; Aloia, T.A.; Abdalla, E.K. et al. CLIP: Improved stratification of advanced hepatocellular carcinoma patients by integrating plasma IGF-I into CLIP score. Oncology.2011; 80: 373-381.

[50]. Helmberger, T.; Dogan, S.; Straub, G.; Schrader, A.; Jungst, C. et al. Liver resection or combined chemoembolization and radiofrequency ablation improve survival in patients with hepatocellular carcinoma. Digestion.2007; 75: 104-112.

[51]. Hsu, C.; Hsia, C.; Huang, Y.; Su, C.; Lin, H. et al. Selecting an optimal staging system for hepatocellular carcinoma: comparison of 5 currently used prognostic models. Cancer. 2010; 116(12): 3006-3014.

[52]. Lopez, J.P. Recent development in the first detection of hepatocellular carcinoma.Clin.Biochem.Rev. $2005 ; 26: 65-79$.

[53]. Jiang, J.; Wu, C.; Shen, Y.; Xu, B.; Zheng, X. et al. Clinical application of determining serum AFP-IgM complexes for diagnosis of small hepatocellular carcinoma. Anticancer Res. 2011; 31(2): 687-691.

[54]. Mohamed, A.A.; Dress, E.A.; Makhlouf, A.A.; Mahmoud, S.; Shalaby, H. et al. Evaluation of human epidermal growth factor as a tumor marker in patients with hepatocellular carcinoma related to hepatitis C virus. Adv. Res. Gastroentero. Hepatol.2016; 1(3).

[55]. Corapcioglu, F.; Turker, G.; Aydogan, A.; Sarper, N.; Duman,C. et al. Serum alpha fetoprotein levels in healthy full term neonates and infants. Marmara Medical Journal.2004; 17(1):1-7.

[56]. El-Serag, H.B.; Marrero, J.A.; Rudolph, L. and Reddy, K.R. Diagnosis and treatment of hepatocellular carcinoma.Gastroenterology. 2008; 134(6): 1752-1763.

[57]. Abdel-Rahman, N.Z.; Alam El-Din, H.M.; Bahnassy, A.A.; Zayed, N.A.; Waleed, S.M. et al. Serum levels of soluble Fas, soluble tumor necrosis factor-receptor II, interleukin-2 receptor and interleukin-8 as early predictors of hepatocellular carcinoma in Egyptian patients with hepatitis C virys genotype-4. Comparative Hepatology.2010; 9:1.

[58]. Huo, T.I.; Wu, J.C. and Lin, H.C. Determination of the optimal model for end-stage liver disease score in patients with small hepatocellular carcinoma undergoing lociregional therapy. Liver Transpl. 2004; 10(12): 1507-1513.

[59]. França, A.V.C.; Junior, J.E.; Lima, B.L.G.; Martinelli, A.L.C. and Carrilho, F.J. Diagnosis, staging and treatment of hepatocellular carcinoma. Braz. J. Med. Biol. Res. 2004; 37(11): 1689-1705

[60]. Llikhan, S.U.; Bilici, M.; Sahin, H.; Akca, A.S.; Can, M. et al. Assessment of the correlation between serum prolidase and alphafetoprotein levels in patients with hepatocellular carcinoma. World J. Gastroenterol.2015; 21: 6999-7007.

[61]. Guan, Y.S.; He, Q. and La, Z. Role of p53 in carcinogenesis, diagnosis and treatment of hepatocellular carcinoma. Journal of Cancer Molecules. 2006; 2(5): 191-197

[62]. Abdel Rehem, R.N. and El-Shikh, W.M. Serum IGF-1, IGF-2 and IGFBP-3 as parameters in the assessment of liver dysfunction in patients with hepatic cirrhosis and in the diagnosis of hepatocellular carcinoma.Hepato-Gastroenterology.2011; 58:949-954

[63]. Qian, J.; Yao, D.; Dong, Z.; Wu, W.; Qiu, L. et al. Characteristics of hepatic IGF-II expression and monitored levels of circulating IGF-II mRNA in metastasis of hepatocellular carcinoma. Am. J. Clin. Pathol. 2010; 134: 799-806

[64]. Yao, D.F.; Dong, Z.Z. and Yao, M. Specific molecular markers in hepatocellular carcinoma. HepatobiliaryPancreat. Dis. Int. 2007; 6: 241-247

[65]. Rashad, N.M.; El-Shal, A.S.; AbdElbary, E.H.; Abo Warda, M.H. and Hegazy, O. Impact of insulin-like growth factor 2, insulinlike growth factor receptor 2, insulin receptor substrate 2 genes polymorphisms on susceptibility and clinicopathological features of hepatocellular carcinoma. Cytokine. 2014; 68(1): 50-58.

[66]. Morace, C.; Cucunato, M.; Bellerone, R.; De Caro, G.; Crino, S. et al. Insulin- like growth factor-II is a useful marker to detect hepatocellular carcinoma? Eur. J. Intern. Med. 2012; 23(6): 157-161.

[67]. Ailing, D.; Lan, F.; Hong, L. and Haoming, H. Relationship between serum levels of IGF-II and HA,PIIP in patients with liver diseases. Journal of Radioimmunology. 2004; 17(3): 181-18.

[68]. Yao, M.; Wang, L.; Yan, M.; Yan, X. and Yao, D. Insulin-like growth factor-II: Molecular targeted therapy for hepatocellular carcinoma, Hepatocellular carcinoma. Future Outlook.Kaseb, A. 2013; (eds).

[69]. Zhou, L.; Liu, J. and Luo, F. Serum markers for detection of HCC. World J. Gastroenterol. 2006; 12(8): 1175-1181

[70]. Yeh. S.H. and Chen, P.J. Gender disparity of hepatocellular carcinoma: the roles of sex hormones. Oncology. 2010; 78(1): 172-179 1181 . 